\title{
The role of advanced neuroimaging in intracerebral hemorrhage
}

\author{
Michael M. McDowell, B.S., Christopher P. Kellner, M.D., Sunjay M. Barton, B.S., \\ Charles B. Mikell, M.D., Eric S. Sussman, B.S., Simon G. Heuts, B.S., \\ and E. Sander Connolly, M.D.
}

Department of Neurological Surgery, Columbia University, New York, New York

\begin{abstract}
In this report, the authors sought to summarize existing literature to provide an overview of the currently available techniques and to critically assess the evidence for or against their application in intracerebral hemorrhage $(\mathrm{ICH})$ for management, prognostication, and research. Functional imaging in ICH represents a potential major step forward in the ability of physicians to assess patients suffering from this devastating illness due to the advantages over standing imaging modalities focused on general tissue structure alone, but its use is highly controversial due to the relative paucity of literature and the lack of consolidation of the predominantly small data sets that are currently in existence. Current data support that diffusion tensor imaging and tractography, diffusion-perfusion weighted MRI techniques, and functional MRI all possess major potential in the areas of highlighting motor deficits, motor recovery, and network reorganization. Novel clinical studies designed to objectively assess the value of each of these modalities on a wider scale in conjunction with other methods of investigation and management will allow for their rapid incorporation into standard practice.

(http://thejns.org/doi/abs/10.3171/2013.1.FOCUS12409)
\end{abstract}

$\begin{array}{lll}\text { KEY WORDS } & \text { intracerebral hemorrhage } \\ \text { functional MRI } & \bullet \quad \text { diffusion tensor imaging }\end{array}$

I NTRACEREBRAL hemorrhage represents the second most common cause of stroke, and is approximately 3 times as likely to result in death within 1 year when compared with ischemic stroke. ${ }^{12,35}$ Advances in imaging options have resulted in major improvements in the prognostication and management of ICH..$^{10,19,22,26,29}$ Magnetic resonance imaging and $\mathrm{CT}$ allowed for these changes to occur by permitting structural validation of clinical symptoms. The advent of functional brain imaging represents another paradigm shift by allowing for the assessment of 3D pathophysiological changes in blood flow, metabolism, absorption, or composition-related symptomology. This provides the distinct advantage of a much more specific measurement of improvement in surviving tissues after insult. These properties also permit the potential assessment of the risk of hemorrhage prior to ictus based on tissue health and provide another modality for use in the diagnosis of hemorrhagic strokes of unclear etiology or type. ${ }^{43}$ In this article we discuss the current and potential uses for functional imaging as it pertains to ICH (Table 1).

\footnotetext{
Abbreviations used in this paper: CAA = cerebral amyloid angiopathy; DTI = diffusion tensor imaging; DWI = diffusion-weighted imaging; fMRI = functional MRI; ICH = intracerebral hemorrhage; PET $=$ positron emission tomography PWI $=$ perfusion-weighted imaging; $\mathrm{tPA}=$ tissue plasminogen activator.
}

\section{Assessment of ICH Risk and Etiology}

The ability to correlate risk factors with identifiable pathophysiological representations of diseased or structurally weakened tissues presents an exciting possibility for elevating the accuracy of risk assessment. One of the groups that might most readily benefit from this strategy is elderly patients being assessed for the possibility of prior or future lobar ICH secondary to cerebral amyloid angiopathy (CAA), which is currently difficult to predict except in retrospect to $\mathrm{ICH}$ or on autopsy. ${ }^{20}$ Investigations related to identifying patients with CAA have been conducted using both DTI and PET. Salat et al..$^{36}$ compared a set of healthy controls to patients who had a clinical diagnosis of CAArelated ICH using DTI and analysis of fractional anisotropy and diffusivity. Diffusivity was not found to be altered; fractional anisotropy was increased in the posterior limb of the internal capsule and subthalamic gray matter bilaterally, but was reduced in the temporal white matter and splenium of the corpus callosum. Changes in fractional anisotropy have also been noted in general ICH studies, but a comparative study has yet to be performed. ${ }^{16,24}$ Should variability in the pattern of changes on fractional anisotropy correlate to alternative causes of ICH, this could provide an additional criterion for diagnosis of CAA as the cause of $\mathrm{ICH}$ rather than hypertension or other causes.

Johnson et al..$^{18}$ investigated the use of a novel com- 
M. M. McDowell et al.

TABLE 1: Current techniques available for functional imaging and their potential role regarding ICH

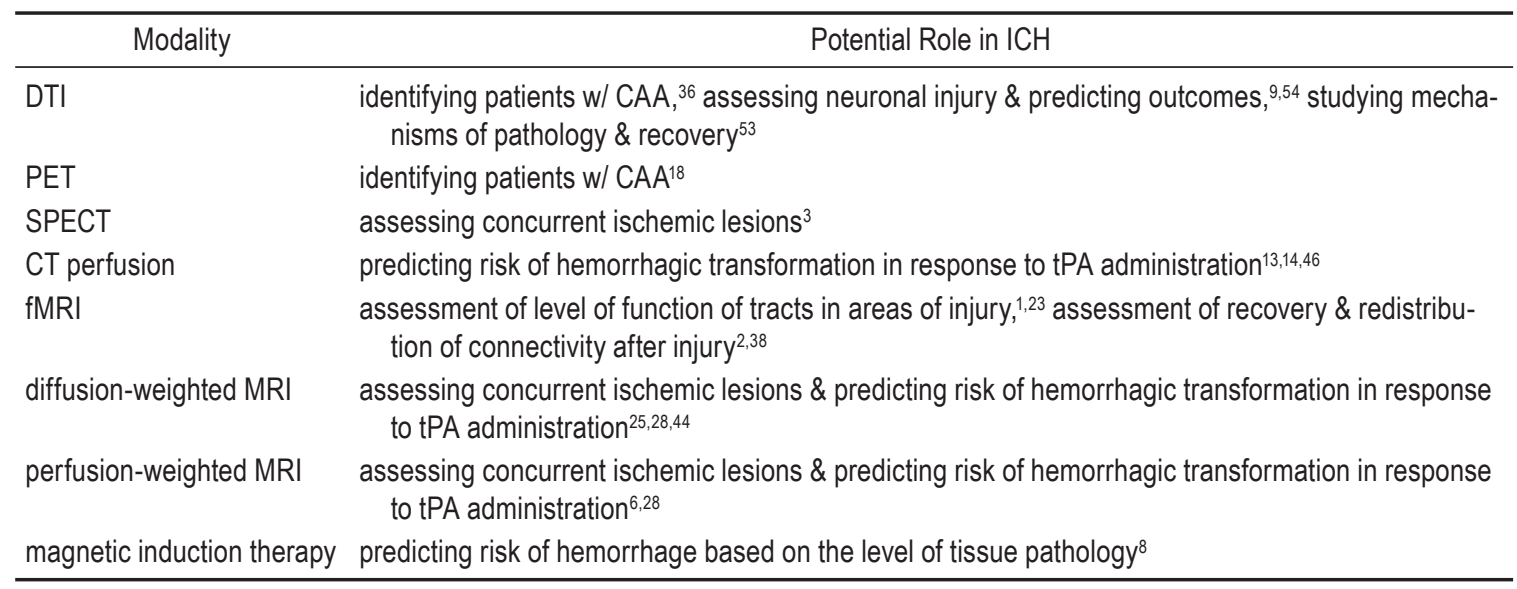

pound capable of binding $\beta$-amyloid components within CAA as a method of direct detection. Findings in 6 cases of probable CAA (diagnosed by biopsy in 4 cases and on the basis of clinical features in 2) were compared with findings in healthy controls and in patients suffering from Alzheimer disease. It was found that the level of PET detection of the compound was greater in patients with CAA than in controls but less than that expected in patients with Alzheimer disease. However, patients with CAA had considerably more occipital lobe deposition than was seen in Alzheimer disease. This distinction not only allows for a reduction in the risk of misdiagnoses, but may also allow for the assessment of CAA even in patients with Alzheimer disease, should a more diffuse level of $\beta$-amyloid deposition be detected than would be expected in this relatively occipital lobe-sparing condition.

The diagnosis of ICH is well established in most cases, but may be delayed initially if the volume is small or the presentation atypical. Chen et al. ${ }^{8}$ recently submitted data investigating the use of magnetic induction tomography, a noninvasive technique utilizing the conductivity of tissue to identify pathological changes. Experimental models with as little as $10 \mathrm{~cm}^{3}$ demonstrated a high level of specificity and sensitivity, but ultimately a higher level of refinement would be required in clinical models to surpass current imaging capabilities. This modality could potentially also assess the presence of underlying lesions.

\section{Management and Monitoring of ICH}

Both MRI and CT scans are routinely used beyond the acute phase of management for prognostication and reevaluation of ICH. However, the prediction of outcome is hampered by the inability to assess on an individual patient level the changes occurring within and near the area of insult. One unique situation in which this is applicable is primary intraventricular hemorrhage and the risk of damage to surrounding white matter tracts. Diffusion tensor imaging has been found to be able to detect diminished levels of integrity and fiber counts within the fornix and alterations in fractional anisotropy and apparent diffusion in the fornix, internal capsule, corona radiata, and corpus callosum in a study of 10 patients with intraventricular hemorrhage compared with 18 healthy controls..$^{52}$ Reduction in fractional anisotropy or fiber count was hypothesized to be indicative of neuronal injury and potentially worse outcome. While an interesting finding, this study by Yeo et al. was performed over a month after ictus, and thus conclusions about the predictive value of these changes for long-term damage to periventricular tissue require additional investigation.

Another area of interest is the ability to assess the level of success at minimizing hypoperfusion and ischemia in tissues adjacent to ICH. Diffusion-perfusion MRI has been shown to provide valuable insight in acute stroke, and recent attempts have been made to apply this to the hemorrhagic model. Magnetic resonance imaging studies performed in the acute phase were found to compete well in detection of hemorrhage when compared with CT, and focal or diffuse ipsilateral hypoperfusion was seen in $35 \%-71 \%$ of cases. ${ }^{27,49}$ Patients demonstrating clinical deterioration later on were also noted to be the only ones with a reduced apparent diffusion coefficient in the perihematomal region in one study, whereas in the other study 1-month follow-up diffusion-weighted MRI demonstrated that $22 \%$ of patients had continued areas of ischemia that had not been present prior to ictus. ${ }^{27,49}$ Siddique et al. ${ }^{42}$ sought to quantify this observation and to describe the chronology of perihematomal changes using SPECT shortly after ictus and then 6-9 months afterward. An improvement in radio-uptake, and thus presumably perfusion, of $15 \%$ or greater was found in all patients at the time of the second scan. The volume of perihematomal brain in which this improvement was noted ranged from 7.2 to $71.3 \mathrm{~cm}^{3}$. This area was felt to represent at least part of the area of perihematomal hypoperfusion and suggests that aggressive measures to maintain perfusion and oxygenation to tissues could improve outcomes. Unfortunately, outcome was not assessed in terms of the level of radiographic improvement within this study. However, these data are yet to be fully validated, and significant debate on the ischemic versus metabolic nature of these findings persists. ${ }^{30,31}$

\section{Prognostication After ICH}

Functional imaging provides the possibility of as- 
sessing the neurological recovery and reorganization of injured tissues in real time and applying this level of activity to predict the end result in both $\mathrm{ICH}$ and other types of hemorrhagic brain injury..$^{37,39,41}$ Of particular promise is the use of DTI in the assessment of corticospinal tract injury after ICH (Fig. 1). In one study, patients with complete loss of hand function secondary to injury to the corona radiata were followed up for 6 months after the insult. Patients with preservation of the corticospinal tract on DTI tractography at the time of insult were found to have the greatest recovery of hand function, whereas those with similarly placed insults that severed the corticospinal tract were found to have the least recovery. ${ }^{9}$ Similarly, assessments of fractional anisotropy along the corticospinal tract in the area of the hematoma were found to predict motor functional outcome at 3 months in a cohort of 17 patients with ICH affecting the putamen and/or thalamus. When scans were performed between 1 and 5 days postictus, patients with the lowest decrease in fractional anisotropy relative to the same area on the nonaffected side or with a ratio greater than 0.8 had the highest level of motor functional recovery at 3 months. Apparent diffusion coefficient values were not found to be predictive in this study. ${ }^{54}$ Perhaps the most interesting discovery of this study was that the ratio of fractional anisotropy was not correlated with hematoma volume or initial deficits in patients enrolled in the study. Patients with large and small hematomas and patients with large and small deficits ultimately demonstrated greater improvement when the ratio was greater than 0.8 . This represents a valuable assessment of outcome that could supplement the current prognostic wisdom of outcome being correlated with measures such as the ICH score and initial deficits, and warrants additional study utilizing additional

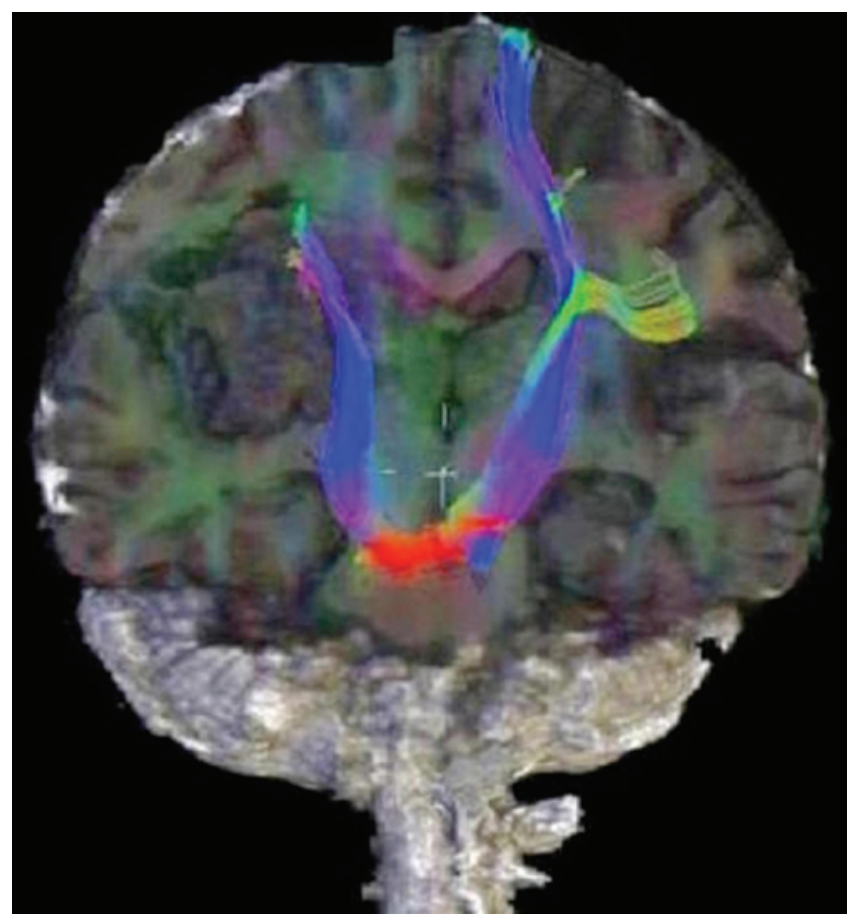

FIG. 1. Diffusion tensor imaging demonstrating interruption of connectivity in the corticospinal tract secondary to right basal ganglia $\mathrm{ICH}$. white matter tracts and types of deficits. The existing data would also benefit from a larger sample size with a wider range of volumes and positions of the hemorrhage.

A similar study by Wang et al. ${ }^{48}$ showed a comparable relationship with fractional anisotropy and independence of hematoma size, but also found that there may be differing diagnostic value when DTI is performed in the acute (3 days postictus) and subacute ( 2 weeks postictus) periods in hemiparetic patients. When DTI was performed in the subacute period, it was found to be more predictive of motor and functional outcome. This may suggest that the initial period of damage and inflammation disrupts the predictive value of DTI, and that once compensatory and salvage mechanisms have begun there is a much clearer picture of the ultimate result. The value of DTI has been associated with a stronger negative predictive value toward motor recovery when the corticospinal tract was not preserved (0.95-1.00 depending on outcome measure) than positive predictive value when preservation was detected (0.59-0.72 depending on outcome measure), but this determination was not based on a comparison with other imaging modalities. ${ }^{15}$

\section{Predicting Hemorrhage After Ischemic Events}

Aggressive measures to promote revascularization using tPA and maintenance of perfusion have to be balanced with the specter of severe hemorrhagic transformation in patients who have suffered ischemic events. Hemorrhagic transformation may occur in a significant fraction of patients, but approximately $6 \%-10 \%$ of patients undergoing tPA treatment have severe or symptomatic hemorrhage comparable to primary ICH.,25 Several options have been presented in the detection of hemorrhage after thrombolysis for the treatment of ischemic lesions. Several studies have demonstrated that the volume of lesions on DWI prior to tPA administration are correlated with risk of hemorrhage, with exact odds ranging from 1.07 to 1.42 per $10 \mathrm{~cm}^{3}$ volume increase. ${ }^{25,44}$ In one study, the interaction of successful reperfusion and DWI volume was found to result in an odds ratio of 1.77 per $10 \mathrm{~cm}^{3}$ volume and, additionally, almost all patients with an $\mathrm{ICH}$ severe enough to result in a decline of more than 3 points on the NIH Stroke Scale were found to have a volume greater than $90 \mathrm{ml}$ when measured on DWI. ${ }^{25}$ In addition to DWI volume, Selim et al. ${ }^{40}$ also noted that risk of hemorrhage was greater in patients with lower apparent diffusion coefficients. Another potential technique that has recently been suggested is the use of low cerebral blood volume detected via perfusion-weighted imaging (PWI), which can be identified by a near complete absence of delivery of gadolinium to an ischemic lesion and thus blood flow as a whole. When more than $2 \mathrm{~cm}^{3}$ of brain volume within the boundaries of the lesion calculated from the DWI was identified as receiving less than the 2.5th percentile of expected cerebral blood flow based on the calculations using the contralateral hemisphere's cerebral blood flow ("Very low cerebral blood volume"), this was highly predictive of some level of parenchymal hemorrhage, and approximately $25 \%$ of such cases were symptomatic. ${ }^{6}$ Perfusion-weighted imaging can be coupled to DWI for additional information regarding the so-called 
"malignant profile" associated with severe ICH secondary to thrombolytic therapy. The DEFUSE-EPITHET trial assessed 111 patients undergoing tPA for stroke using pretreatment DWI and PWI modalities. It was found that $89 \%$ of patients with a PWI-detected brain volume of $85 \mathrm{~cm}^{3}$ with a "Tmax" (time until the theoretical maximal amount of residue function) greater than 8 seconds who achieved reperfusion had a modified Rankin Scale score of 5 or 6 at 90 days. Of these, only $67 \%$ were secondary to at least some level of parenchymal hemorrhage, which was also significantly more likely using the $85-\mathrm{cm}^{3}$ cutoff. ${ }^{28}$

Due to the time constraints involved in the administration of tPA, there has been significant interest in the utilization of CT perfusion studies to measure the blood-brain permeability as a surrogate for hemorrhagic risk. Inoue et al. ${ }^{14}$ reported on a series of 42 patients who underwent CT perfusion scans within 3 hours of symptoms. A definition of malignancy of $53 \mathrm{~cm}^{3}$ or more of ischemic core (brain tissue with $<30 \%$ of median contralateral hemisphere blood flow) selected with a specificity of $100 \%$ but a $67 \%$ sensitivity for poor outcome, defined as a modified Rankin Scale score of 5 or 6 . However, only 5 cases were identified as malignant and patients in only 2 of these 5 had hemorrhage. Larger studies must be conducted prior to any recommendation of excluding patients based on this criterion. Blood-brain barrier measurements via perfusion $\mathrm{CT}$ in an additional retrospective study provided similar support for this modality, but with differences in the predictive value of an unfavorable change in NIH Stroke Scale score by 5 or more (sensitivity of $100 \%$ and specificity of $79 \%) .{ }^{13}$ In addition, only $38 \%$ of outcomes were due to hemorrhage specifically, which raises concerns about the interobserver reliability. A comparison study of DWI and CT perfusion in 96 patients presenting with stroke was performed by Souza et al. ${ }^{46}$ and demonstrated no statistical difference in predictive value of outcomes. This study did not have sufficient data to specifically assess the value of predicting $\mathrm{ICH}$ after tPA administration due to only 3 cases of postischemic ICH being recorded in the 96 patients included in the study, but it did establish that there was approximate equivalence in the predictive value within the general stroke cohort. With additional investigations, this modality may provide an excellent alternative method of evaluation for cases in which time is a crucial factor and patients who are deemed to be at high risk for secondary ICH.

\section{Understanding the Mechanisms of Pathology and Recovery}

The exact mechanisms by which and extent to which injured tissue responds and recovers from ICH are to a great extent unknown. The real-time expression of recovery using functional imaging is in many ways an ideal mechanism of understanding ICH in human patients. Following ischemic stroke, patients with motor deficits demonstrate activation of premotor, parietal, and contralateral primary motor cortex when participating in motor tasks with the paretic hand; ${ }^{4}$ over time, this activation comes to resemble control activation (for example, activation centered in the ipsilateral primary motor cortex [M1] along with related ipsilateral motor structures). ${ }^{50,51}$ This pattern of initially widespread activation with subsequent consolidation to fewer, more control-like structures has now been reproduced extensively and confirmed in a recent meta-analysis. ${ }^{32}$ However, the clinical significance of these activation patterns has been hotly debated. One school of thought suggests that contralateral M1 activation is always dysfunctional and therapeutic strategies should be directed toward inhibiting it and restoring balance. ${ }^{3,5}$ Another interpretation suggests that contralateral M1 activation is required for early recovery and becomes inhibitory/pathological at later time points..$^{33,34}$ These studies were supported by studies showing that contralateral transcranial magnetic stimulation improved motor performance on finger-tapping tests in control subjects ${ }^{21}$ as well as on kinematic measures in chronically paretic (>6 months) ischemic stroke patients. ${ }^{47}$ Future studies in both ischemic and hemorrhagic stroke are underway to better elucidate the mechanisms involved.

Studies have demonstrated the potential for use of these modalities in both early and late periods after ICH. Jang et al. ${ }^{17}$ compared findings in 44 patients with chronic deficits in hand function after basal ganglia or corona radiata ICH with findings in normal controls. While numerous tracts were reduced in connectivity, it was found that the strongest predictors of hand function were viable tracts in the ipsilateral basal ganglia, thalamus, and pyramids. The ipsilateral primary motor cortex was also correlated with hand function when preserved, but to a substantially lower degree. Understanding the exact pathways used by corticospinal fibers has been a highly sought-after target of study, given the frequent motor deficits in $\mathrm{ICH}$, and could potentially allow for prognostication as well as targets for eventual rehabilitation. The fact that the connectivity of the primary motor cortex was less predictive of hand function than more caudal connections may be due to the condition of the patients, but could potentially also imply that chronic changes occur to allow for redistribution of the final point of control to nonaffected areas with greater flexibility than previously expected. The strong correlation with the basal ganglia and thalamus would then potentially indicate that the connections required to redistribute function are subcortical in nature and are more crucial in terms of preservation. In another study, ${ }^{53} 43$ patients with prior ICH confined to the corona radiata or posterior limb of the internal capsule were compared with healthy controls to correlate complex motor tasks such as locomotion to corticospinal tracts related to the locomotor centers using DTI. Connectivity was seen to correlate with inability, impaired ability, and normal ability to walk, with connectivity being clearly reduced in $\mathrm{ICH}$ patients and in many cases reduced at discernible levels for complete versus partial loss of ambulation. The ability to predict the extent of injury and functional deficit on a functional rather than just structural level is a highly tantalizing prospect, given the severity of illness and the difficulties that can occur when examining disoriented or comatose patients during the immediate postictal period. However, the well-established hazards of a prolonged MRI series in a patient in unstable condition or a patient with relative contraindications must be taken into strong consideration as well. ${ }^{45}$

Jang et al. ${ }^{17}$ also presented a synopsis of motor recov- 
ery after ICH using DTI and fMRI. There were demonstrable deficits and recovery in both modalities as motor recovery was regained, but quantitative data were not provided to allow for direct comparison. Functional MRI has recently become of more interest in ICH. Whereas previously this modality has had less utility due to the need for attentiveness or motor function, some progress has been made and more is expected with the rise in the use of resting-state fMRI as a method of gauging activity between existing fibers rather than the existence of connections. ${ }^{1,23}$ Using functional connectivity measures, it may be possible to develop a sophisticated model of recovery from ICH in normal and pathological circumstances. In particular, no study has adopted a multimodal approach to the presumed "inhibitory" effect of the contralateral M1 on recovery. ${ }^{2,38}$ Interhemispheric inhibition has been studied extensively using task-based fMRI, ${ }^{11}$ but a combined approach using structural and functional connectivity to develop a model of functional connectivity has not yet been attempted.

\section{Conclusions}

Intracerebral hemorrhage results in serious morbidity for surviving patients, often causing loss of independence and motor function. The increasing use of functional imaging as a tool not only for research, but also for the management of clinical scenarios, represents a major step forward in the effort to reduce the hardships of patients through improved understanding and more sophisticated prognostication. The important role of motor deficits in the ICH spectrum highlights the value of DTI tractography and diffusion-perfusion-related techniques, whereas recovery and reorganization of neurological networks provides potential for increased utilization of fMRI modalities.

\section{Disclosure}

Michael McDowell and Eric Sussman are recipients of a clinical research fellowship from the Doris Duke Charitable Foundation.

Author contributions to the study and manuscript preparation include the following. Conception and design: McDowell. Acquisition of data: McDowell, Barton. Drafting the article: McDowell, Kellner, Barton. Critically revising the article: Connolly, McDowell, Kellner, Mikell, Sussman, Heuts. Reviewed submitted version of manuscript: all authors. Approved the final version of the manuscript on behalf of all authors: Connolly.

\section{References}

1. Abutalebi J, Rosa PA, Tettamanti M, Green DW, Cappa SF: Bilingual aphasia and language control: a follow-up fMRI and intrinsic connectivity study. Brain Lang 109:141-156, 2009

2. Bütefisch CM, Wessling M, Netz J, Seitz RJ, Hömberg V: Relationship between interhemispheric inhibition and motor cortex excitability in subacute stroke patients. Neurorehabil Neural Repair 22:4-21, 2008

3. Calautti C, Jones PS, Naccarato M, Sharma N, Day DJ, Bullmore ET, et al: The relationship between motor deficit and primary motor cortex hemispheric activation balance after stroke: longitudinal fMRI study. J Neurol Neurosurg Psychiatry 81:788-792, 2010

4. Calautti C, Leroy F, Guincestre JY, Baron JC: Dynamics of motor network overactivation after striatocapsular stroke: a longitudinal PET study using a fixed-performance paradigm. Stroke 32:2534-2542, 2001

5. Calautti C, Naccarato M, Jones PS, Sharma N, Day DD, Carpenter AT, et al: The relationship between motor deficit and hemisphere activation balance after stroke: a $3 \mathrm{~T}$ fMRI study. Neuroimage 34:322-331, 2007

6. Campbell BC, Christensen S, Butcher KS, Gordon I, Parsons MW, Desmond PM, et al: Regional very low cerebral blood volume predicts hemorrhagic transformation better than diffusion-weighted imaging volume and thresholded apparent diffusion coefficient in acute ischemic stroke. Stroke 41:8288,2010

7. Caplan LR: Tissue plasminogen activator for acute ischemic stroke. N Engl J Med 341:1240-1241, 1999

8. Chen Y, Yan M, Chen D, Hamsch M, Liu H, Jin H, et al: Imaging hemorrhagic stroke with magnetic induction tomography: realistic simulation and evaluation. Physiol Meas 31:809827,2010

9. Cho SH, Kim DG, Kim DS, Kim YH, Lee CH, Jang SH: Motor outcome according to the integrity of the corticospinal tract determined by diffusion tensor tractography in the early stage of corona radiata infarct. Neurosci Lett 426:123-127, 2007

10. Fiebach JB, Schellinger PD, Gass A, Kucinski T, Siebler M, Villringer A, et al: Stroke magnetic resonance imaging is accurate in hyperacute intracerebral hemorrhage: a multicenter study on the validity of stroke imaging. Stroke 35:502-506, 2004

11. Grefkes C, Nowak DA, Eickhoff SB, Dafotakis M, Küst J, Karbe H, et al: Cortical connectivity after subcortical stroke assessed with functional magnetic resonance imaging. Ann Neurol 63:236-246, 2008

12. Hartmann A, Rundek T, Mast H, Paik MC, Boden-Albala B, Mohr JP, et al: Mortality and causes of death after first ischemic stroke: the Northern Manhattan Stroke Study. Neurology 57:2000-2005, 2001

13. Hom J, Dankbaar JW, Soares BP, Schneider T, Cheng SC, Bredno J, et al: Blood-brain barrier permeability assessed by perfusion $\mathrm{CT}$ predicts symptomatic hemorrhagic transformation and malignant edema in acute ischemic stroke. AJNR Am J Neuroradiol 32:41-48, 2011

14. Inoue M, Mlynash M, Straka M, Lansberg MG, Zaharchuk G, Bammer R, et al: Patients with the malignant profile within 3 hours of symptom onset have very poor outcomes after intravenous tissue-type plasminogen activator therapy. Stroke 43: 2494-2496, 2012

15. Jang SH, Ahn SH, Sakong J, Byun WM, Choi BY, Chang CH, et al: Comparison of TMS and DTT for predicting motor outcome in intracerebral hemorrhage. J Neurol Sci 290:107-111, 2010

16. Jang SH, Byun WM, Han BS, Park HJ, Bai DS, Ahn YH, et al: Recovery of a partially damaged corticospinal tract in a patient with intracerebral hemorrhage: a diffusion tensor image study. Restor Neurol Neurosci 24:25-29, 2006

17. Jang SH, Kim SH, Cho SH, Choi BY, Cho YW: Demonstration of motor recovery process in a patient with intracerebral hemorrhage. NeuroRehabilitation 22:141-145, 2007

18. Johnson KA, Gregas M, Becker JA, Kinnecom C, Salat DH, Moran EK, et al: Imaging of amyloid burden and distribution in cerebral amyloid angiopathy. Ann Neurol 62:229-234, 2007

19. Kidwell CS, Chalela JA, Saver JL, Starkman S, Hill MD, Demchuk AM, et al: Comparison of MRI and CT for detection of acute intracerebral hemorrhage. JAMA 292:1823-1830, 2004

20. Knudsen KA, Rosand J, Karluk D, Greenberg SM: Clinical diagnosis of cerebral amyloid angiopathy: validation of the Boston criteria. Neurology 56:537-539, 2001

21. Kobayashi M, Hutchinson S, Théoret H, Schlaug G, PascualLeone A: Repetitive TMS of the motor cortex improves ipsilat- 
eral sequential simple finger movements. Neurology 62:91-98, 2004

22. Kothari RU, Brott T, Broderick JP, Barsan WG, Sauerbeck LR, Zuccarello M, et al: The ABCs of measuring intracerebral hemorrhage volumes. Stroke 27:1304-1305, 1996

23. Kremer S, Nicolas-Ong C, Schunck T, Schenck M, Collange $\mathrm{O}$, Mutschler V, et al: Usefulness of functional MRI associated with PET scan and evoked potentials in the evaluation of brain functions after severe brain injury: preliminary results. J Neuroradiol 37:159-166, 2010

24. Kwak SY, Yeo SS, Choi BY, Chang CH, Jang SH: Corticospinal tract change in the unaffected hemisphere at the early stage of intracerebral hemorrhage: a diffusion tensor tractography study. Eur Neurol 63:149-153, 2010

25. Lansberg MG, Thijs VN, Bammer R, Kemp S, Wijman CA, Marks MP, et al: Risk factors of symptomatic intracerebral hemorrhage after tPA therapy for acute stroke. Stroke 38:2275-2278, 2007

26. Linfante I, Llinas RH, Caplan LR, Warach S: MRI features of intracerebral hemorrhage within 2 hours from symptom onset. Stroke 30:2263-2267, 1999

27. Menon RS, Burgess RE, Wing JJ, Gibbons MC, Shara NM, Fernandez S, et al: Predictors of highly prevalent brain ischemia in intracerebral hemorrhage. Ann Neurol 71:199-205, 2012

28. Mlynash M, Lansberg MG, De Silva DA, Lee J, Christensen $S$, Straka M, et al: Refining the definition of the malignant profile: insights from the DEFUSE-EPITHET pooled data set. Stroke 42:1270-1275, 2011

29. Morgenstern LB, Hemphill JC III, Anderson C, Becker K, Broderick JP, Connolly ES Jr, et al: Guidelines for the management of spontaneous intracerebral hemorrhage: a guideline for healthcare professionals from the American Heart Association/ American Stroke Association. Stroke 41:2108-2129, 2010

30. Orakcioglu B, Becker K, Sakowitz OW, Unterberg A, Schellinger PD: Serial diffusion and perfusion MRI analysis of the perihemorrhagic zone in a rat ICH model. Acta Neurochir Suppl 103:15-18, 2008

31. Prabhakaran S, Naidech AM: Ischemic brain injury after intracerebral hemorrhage: a critical review. Stroke 43:22582263, 2012

32. Rehme AK, Eickhoff SB, Rottschy C, Fink GR, Grefkes C: Activation likelihood estimation meta-analysis of motor-related neural activity after stroke. Neuroimage 59:2771-2782, 2012

33. Rehme AK, Eickhoff SB, Wang LE, Fink GR, Grefkes C: Dynamic causal modeling of cortical activity from the acute to the chronic stage after stroke. Neuroimage 55:1147-1158, 2011

34. Rehme AK, Fink GR, von Cramon DY, Grefkes C: The role of the contralesional motor cortex for motor recovery in the early days after stroke assessed with longitudinal FMRI. Cereb Cortex 21:756-768, 2011

35. Sacco S, Marini C, Toni D, Olivieri L, Carolei A: Incidence and 10-year survival of intracerebral hemorrhage in a population-based registry. Stroke 40:394-399, 2009

36. Salat DH, Smith EE, Tuch DS, Benner T, Pappu V, Schwab KM, et al: White matter alterations in cerebral amyloid angiopathy measured by diffusion tensor imaging. Stroke 37:1759-1764, 2006

37. Sato K, Shimizu H, Fujimura M, Inoue T, Matsumoto Y, Tominaga T: Acute-stage diffusion-weighted magnetic resonance imaging for predicting outcome of poor-grade aneurysmal subarachnoid hemorrhage. J Cereb Blood Flow Metab 30:1110-1120, 2010

38. Schambra HM, Sawaki L, Cohen LG: Modulation of excitability of human motor cortex (M1) by $1 \mathrm{~Hz}$ transcranial magnetic stimulation of the contralateral M1. Clin Neurophysiol 114:130-133, 2003
39. Schweizer TA, Al-Khindi T, Loch Macdonald R: Diffusion tensor imaging as a surrogate marker for outcome after perimesencephalic subarachnoid hemorrhage. Clin Neurol Neurosurg 114:798-800, 2012

40. Selim M, Fink JN, Kumar S, Caplan LR, Horkan C, Chen Y, et al: Predictors of hemorrhagic transformation after intravenous recombinant tissue plasminogen activator: prognostic value of the initial apparent diffusion coefficient and diffusion-weighted lesion volume. Stroke 33:2047-2052, 2002

41. Shimoda M, Hoshikawa K, Shiramizu H, Oda S, Yoshiyama M, Matsumae M: Clinical implications of subarachnoid clots detected by diffusion-weighted imaging in the acute stage of aneurysm rupture. Neurol Med Chir (Tokyo) 50:192-199, 2010

42. Siddique MS, Fernandes HM, Wooldridge TD, Fenwick JD, Slomka P, Mendelow AD: Reversible ischemia around intracerebral hemorrhage: a single-photon emission computerized tomography study. J Neurosurg 96:736-741, 2002

43. Siddiqui FM, Bekker SV, Qureshi AI: Neuroimaging of hemorrhage and vascular defects. Neurotherapeutics 8:28-38, 2011

44. Singer OC, Humpich MC, Fiehler J, Albers GW, Lansberg MG, Kastrup A, et al: Risk for symptomatic intracerebral hemorrhage after thrombolysis assessed by diffusion-weighted magnetic resonance imaging. Ann Neurol 63:52-60, 2008

45. Singer OC, Sitzer M, du Mesnil de Rochemont R, NeumannHaefelin T: Practical limitations of acute stroke MRI due to patient-related problems. Neurology 62:1848-1849, 2004

46. Souza LC, Payabvash S, Wang Y, Kamalian S, Schaefer P, Gonzalez RG, et al: Admission CT perfusion is an independent predictor of hemorrhagic transformation in acute stroke with similar accuracy to DWI. Cerebrovasc Dis 33:8-15, 2012

47. Takeuchi N, Chuma T, Matsuo Y, Watanabe I, Ikoma K: Repetitive transcranial magnetic stimulation of contralesional primary motor cortex improves hand function after stroke. Stroke 36:2681-2686, 2005

48. Wang DM, Li J, Liu JR, Hu HY: Diffusion tensor imaging predicts long-term motor functional outcome in patients with acute supratentorial intracranial hemorrhage. Cerebrovasc Dis 34:199-205, 2012

49. Warach S, Gaa J, Siewert B, Wielopolski P, Edelman RR: Acute human stroke studied by whole brain echo planar diffusionweighted magnetic resonance imaging. Ann Neurol 37:231241, 1995

50. Ward NS, Brown MM, Thompson AJ, Frackowiak RS: Neural correlates of motor recovery after stroke: a longitudinal fMRI study. Brain 126:2476-2496, 2003

51. Ward NS, Brown MM, Thompson AJ, Frackowiak RS: Neural correlates of outcome after stroke: a cross-sectional fMRI study. Brain 126:1430-1448, 2003

52. Yeo SS, Choi BY, Chang CH, Jung YJ, Ahn SH, Son SM, et al: Periventricular white matter injury by primary intraventricular hemorrhage: a diffusion tensor imaging study. Eur Neurol 66:235-241, 2011

53. Yeo SS, Lee DG, Choi BY, Chang CH, Jung YJ, Kim SH, et al: Neural connectivity of the pedunculopontine nucleus in relation to walking ability in chronic patients with intracerebral hemorrhage. Eur Neurol 67:226-231, 2012

54. Yoshioka H, Horikoshi T, Aoki S, Hori M, Ishigame K, Uchida $\mathrm{M}$, et al: Diffusion tensor tractography predicts motor functional outcome in patients with spontaneous intracerebral hemorrhage. Neurosurgery 62:97-103, 2008

Manuscript submitted December 14, 2012.

Accepted January 23, 2013.

Please include this information when citing this paper: DOI: 10.3171/2013.1.FOCUS12409.

Address correspondence to: E. Sander Connolly, M.D., The Neurological Institute, 710 West 168th Street, New York, New York 10032.email: esc5@columbia.edu. 